\title{
Article
}

\section{The impact of short periods of match congestion on injury risk and patterns in an elite football club}

Carling, C., McCall, A., Le Gall, F., and Dupont, G.

Available at https://clok.uclan.ac.uk/14080/

Carling, C. orcid iconORCID: 0000-0002-7456-3493, McCall, A., Le Gall, F., and Dupont, G. (2015) The impact of short periods of match congestion on injury risk and patterns in an elite football club. British Journal of Sports Medicine, 50 (12). pp. 674-678. ISSN 0306-3674

It is advisable to refer to the publisher's version if you intend to cite from the work. http://dx.doi.org/10.1136/bjsports-2015-095501

For more information about UCLan's research in this area go to http://www.uclan.ac.uk/researchgroups/ and search for < name of research Group>.

For information about Research generally at UCLan please go to http://www.uclan.ac.uk/research/

All outputs in CLoK are protected by Intellectual Property Rights law, including Copyright law. Copyright, IPR and Moral Rights for the works on this site are retained by the individual authors and/or other copyright owners. Terms and conditions for use of this material are defined in the policies page.

\section{CLoK}

Central Lancashire online Knowledge www.clok.uclan.ac.uk

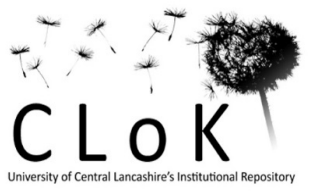


This is a pre-proof corrected manuscript, as accepted for publication, of an article published by BMJ Publishing Group in British Journal of Sports Medicine on $18^{\text {th }}$ December 2015, available at: http://bjsm.bmj.com/content/early/2015/12/18/bjsports-2015-095501.abstract

5 Title: The impact of short periods of match congestion on injury risk and patterns in an elite

6 football club

7

8 Authors: Christopher Carling ${ }^{1,2}$, Alan McCall ${ }^{2,3}$, Franck Le Gall ${ }^{2}$, Gregory Dupont ${ }^{2,4}$

\section{Institution:}

11 Institute of Coaching and Performance, University of Central Lancashire, UK

12 22LOSC Lille Métropole Football Club, Research and Development Department, Camphin-en-Pévèle,

13 France

$14{ }^{3}$ Research Department for Sports and Exercise Science, Napier University, Edinburgh, UK

$15{ }^{4}$ Univ Lille Nord de France, 59000 Lille, France - UDSL, EA 4488

16

\section{Corresponding author:}

18 Christopher Carling

19 Correspondence: Institute of Coaching and Performance, University of Central Lancashire, Preston,

20 UK

21 Phone: 00.33.6.0392 1863

22 Fax: 00.33.1.48910793

23 Email: chris.carling@free.fr

26 Funding:

27 There was no funding received for this study

29 Competing interests:

30 The authors declare no conflicts of interest 
1 Title: The impact of short periods of match congestion on injury risk and patterns in an elite

2 football club

3

4 Running head: Injury in elite football

6 Abstract

7 Background: The effect of fixture congestion on injury rates and patterns has received scarce attention in

8 elite football and existing investigations have not accounted for player rotation or examined the temporal

9 distribution and potential cause of injuries.

10 Aim: To prospectively investigate the epidemiology of injury during short periods of fixture congestion

11 in a professional football club.

12 Methods: Over a 6-season period, exposure time and injury data were compared in the same players ( $\mathrm{n}=25$

13 [14 individuals]) when participating in two frequently occurring short congested fixture cycles in 14 comparison to match-play outside these cycles. 1) two successive matches separated by an interval 15 totalling $\leq 3$ days calculated immediately from the end of play in match 1 to the beginning of play in match

$162 ; 2$ ) three successive matches separated by $\leq 4$-day intervals commencing the day immediately after each 17 match.

18 Results: In 2-match congestion cycles, incidence rate ratios (IRR) showed there was a higher risk of injury

19 in the final 15-minutes of play in the second match in comparison to match-play outside the cycles (IRR:

203.1 [95\% CI 1.1 to 9.3], $\mathrm{p}=0.0400$ ). A greater risk of injury overall (IRR: 2.0 [95\% CI 1.1 to 3.8],

$21 \mathrm{p}=0.0345)$ and in the 1st-half of play (2.6 [1.1 to 6,5], $\mathrm{p}=0.0386)$, and risk of ankle sprains (10.4 [95\%

22 CI 1.9 to 57.9], $\mathrm{p}=0.0068$ ) and non-contact injuries due to a 'change in direction' (IRR: 7.8 [1.3 to 46.8],

$23 \mathrm{p}=0.0243$ ) was observed in the final match of 3-match congestion cycles in comparison to match-play

24 outside the cycles.

25 Conclusion: Injury rates and patterns were affected in the same elite football players when competing in

26 short congested fixture cycles in comparison to match-play outside the cycles.

28 Key terms: injuries, soccer, fixture congestion, fatigue 


\section{Introduction}

2 In contemporary elite football, clubs can compete in a large number of matches across the season many

3 of which are played within a tight time frame. Match congestion is regarded as a threat to team

4 performance and player health. ${ }^{1}$ Yet surprisingly, only a limited number of studies have examined the

5 effects of match congestion on injury risk and have reported contrasting findings. In two investigations

6 examining the impact of short congested cycles that frequently occur across the season, injury risk in

7 match-play was comparable in consecutive matches separated by a short interval ( $\leq 3$-days) versus those

8 following a longer interval ( $\geq 4$-days). ${ }^{2,3}$ In contrast, a five-fold increase in injury incidence was observed

9 when players participated in two successive matches played within a 4-day period compared to matches

10 separated by 6-day intervals. ${ }^{4}$ Regarding the risk over longer periods of match congestion, one study ${ }^{5}$

11 reported a significant increase in injury incidence while another ${ }^{6}$ did not. However, the majority of

12 previous studies share a limitation in that data were collected and analysed at 'team' level and did not

13 account for player rotation. Therefore the true risk of injury in the same players when exposed to periods

14 of match congestion in comparison to match-play outside congested periods is generally unknown.

15 Limited information is available on injury type and location over short match congestion cycles

16 in elite football. One investigation in 27 elite European football teams reported similar muscle injury rates

17 in matches (all competition formats) with $\leq 3$-days recovery versus matches with $\geq 4$-days recovery. ${ }^{2}$ In

18 contrast, a significant increase in sustaining a muscle injury was observed in league matches separated

19 by a short interval ( $\leq 4$-days) compared to longer intervals ( $\geq 6$-days). Again, the potential effects of player

20 rotation were unaccounted for by the authors. In addition, previous epidemiological research has shown

21 that injury rates generally and the frequency of ankle sprains and muscle strains increase during the latter

22 stages of match-play. ${ }^{7-9}$ However, no information exists on the potential effects of fixture congestion on

23 the temporal distribution of injuries. Similarly, no data are available on the causes of injuries incurred 24 over congested periods of play.

25 The aim of this study was to investigate injury rates and patterns during short periods of fixture 26 congestion in top-level players belonging to a professional football club.

\section{Methods}

29 This prospective observational study investigated injuries sustained in match-play over a 6-season period

30 in a cohort of male professional football players belonging to the first-team squad of a French Ligue 1

31 Club (2009-15). While all data arose as a condition of employment in which players were routinely 32 monitored over the course of the competitive season ${ }^{10}$, approval for the study from the present club was obtained. To ensure confidentiality, all data were anonymised before analysis.

Over the six seasons, the club played in European Competition on five occasions: 3 UEFA

35 Champions League and 2 UEFA Europa League participations. Individual exposure time to all official 36 club competitions and national team play (including tournament qualification and friendly matches) was recorded for each player belonging to the first-team squad by the club's sports scientist. 
To examine the risk of injury during fixture congestion, exposure time and injury data were

2 collected over two commonly occurring short congested club and national team match cycles and

3 compared to matches outside these cycles: 1) 2-match congestion cycles: two successive matches

4 separated by a time interval totalling $\leq 3$ days $(\leq 72 \mathrm{hrs})$ calculated immediately from the end of play in

5 match 1 to the beginning of play in match 2 (e.g., match 1 played on Thursday at $21 \mathrm{H}$ and match 2 on

6 Sunday at 17H); 2) 3-match congestion cycle: three matches played successively with each separated by

7 a $\leq 4$-day period commencing the day immediately after each match (e.g., match 1 played on Sunday at

$817 \mathrm{H}$, match 2 on Thursday at $21 \mathrm{H}$ and match 3 on Sunday at $21 \mathrm{H}$ ). These short congestion cycles were

9 selected due to their frequent occurrence across the season ${ }^{11,12}$ while the time intervals between matches

10 are associated with a greater injury risk $^{2,4}$ and incomplete physiological and physical recovery ${ }^{13}$. Match-

11 play inclusion criteria ${ }^{4}$ required players to have participated in: 1) $\geq 75$-minutes play in matches played

12 outside the above periods of fixture congestion; 2) $\geq 75$-minutes play in the first match in the 2-match

13 congestion cycles and any participation time in the second match;3) $\geq 75$-minutes play in the first and

14 second games in the 3-match congestion cycle and any participation time in match 3 . Participation in both

15 congested cycles on a minimum of three occasions across the competitive season was deemed necessary

16 for inclusion. This stringent inclusion criteria subsequently provided repeated measures in a cumulated

17 total of 25 (14 individual players) out of a possible 150 cumulated players ( 35 individual players) who

18 participated over the 6-season span.

19 The injuries sustained in match-play were prospectively diagnosed and documented by the same

20 sports physician over the entire study period. Injuries incurred during national duties were also diagnosed

21 (after consultation with respective national team medical staff where necessary) and documented on the

22 player's return to the club. The definitions of injury used were based on those recommended by

23 International Football Injury Consensus Groups. ${ }^{14,15}$ Injury: time-loss injury resulting from playing

24 football and leading to a player being unable to fully participate in future training or match play

25 independent of whether a training session actually took place on the day following injury or the player

26 was selected to play in the next match. The layoff time of the injury was determined according to the

27 number of days the player was absent from and unable to take full part in training or competition. Injury

28 type and location and whether the injury was recurrent were also documented by the physician. A

29 recurrent injury was described as an injury of the same type and at the same site as an index injury and

30 that occurred within 2 months after a player's return to full participation from the index injury.

31 Information on the time and cause of injuries sustained in competition was firstly collected via direct

32 questioning of the player by the club physician. If further confirmation was required, the club physician

33 and sports scientist visualised the match video recording. If there was cause for doubt on the time and/or

34 cause of injuries and consensus between player, physician and sports scientist was not achieved, then

35 these variables were classified as 'unknown'.

36 Standard statistical procedures were used to calculate frequencies, means and standard deviations.

37 The incidence of injury (number of injuries per 1000hours exposure to play) was calculated for the final 
match in both congested cycles and for match-play outside these cycles. Injury incidences and incidence rate ratios (IRR) for comparisons are reported and presented with 95\% Confidence Intervals (95\%CI). IRR were also tested for significance using $\mathrm{Z}$ statistics. ${ }^{2}$ The mean layoff time for injuries across the two congested match cycles was compared to matches outside these cycles using a paired t-test. A p-value of $<0.05$ was considered statistically significant.

9 Over the 6-season study span, 2- and 3-match congestion cycles occurred on 10.8 \pm 5.5 and 9.7 \pm 3.9 10 occasions per season. On average per season, the players participated on $7.4 \pm 3.4$ and $3.4 \pm 1.6$ occasions 11 in all matches across 2- and 3-match congestion cycles and on 19.4 \pm 6.9 occasions in matches outside 12 these cycles. Total exposure time to the final match in 2- and 3-match congestion cycles and in matches outside these cycles for all players equated to 269.2, 138.9 and 724.0 hours play.

A total of 34 injuries were sustained in match-play outside congestion cycles while 19 and 13 injuries were incurred in the final matches in 2- and 3-match congestion cycles. In comparison to the incidence values in matches outside the congestion cycles (Figure 1), there was a higher risk of injury albeit non-significant in the final match in the 2-match congestion cycle (47.0 [95\%CI 31 to 63] vs. 70.6 [95\%CI: 39 to 102], IRR: 1.5 [95\%CI 0.9 to 2.6], $\mathrm{p}=0.1553$ ) and a significantly greater risk in the final match in the 3-match congestion cycle $(47.0$ [95\% CI 31 to 63] vs. 93.6 [95\% CI 43 to 144], IRR: 2.0 [95\%CI 1.1 to 3.8], $\mathrm{p}=0.0345$ ).

The mean layoff time in days for injuries did not differ significantly for those sustained in matchplay outside the cycles injury compared to the final matches in the 2- and 3-match congestion cycles ( $6.9 \pm 2.9$ vs. $6.2 \pm 3, p=0.523$ and vs. $4.3 \pm 3.0$ days, $p=0.145$ ). In match-play outside the cycles compared to that in the final matches in the 2-match congestion cycle, the incidence of reinjury was higher, albeit non significantly (5.5 [95\% CI 0 to 11 ] vs. 3.7 [95\%CI -4 to 11 ], IRR=0.7 [95\%CI 0.1 to 6.0 ], $\mathrm{p}=0.6390)$. No recurrences of injury occurred in the final matches in the 3-match congestion cycle.

A higher albeit non significant trend was observed for the risk of muscle strains, particularly to the hamstring region, in the final matches in the 2- and 3-match congestion cycles compared to that observed in match-play outside the congested cycles (Table 1). In comparison to the incidence of joint sprains incurred in match-play outside congestion cycles (Figure 1), again there was a non-significant trend for a higher risk of these injuries in the final match in the 2-match congestion cycle (14.9 [95\% CI 0 to 29 ] vs. 4.1 [95\% CI 0 to 9], IRR: 3.6 [95\% CI 0.8 to 16.2], $\mathrm{p}=0.0947$ ) while a significantly greater risk was observed in the final match in the 3-match congestion cycle $(28.8$ [95\% CI 1 to 57] vs. 4.1 [95\% CI 0 to 9], IRR: 7.0 [95\% CI 1.5 to 31.4], $\mathrm{p}=0.0112$ ). The risk of sprains to the ankle region was significantly higher ([28.8 [95\%CI 1 to 57.0$]$ vs. 2.8 [95\%CI -1 to 7 , IRR: 10.4 [95\%CI 1.9 to 57.9$], \mathrm{p}=0.0068$ ) in the 
Despite a non-significant difference, there was a higher risk of contact injury during match-play

2 outside the cycles compared to for the final match in the 2- and 3-match congestion cycles: 22.1 (95\% CI

311 to 33 ) vs. 26.0 (95\%CI 7 to 45 ) vs. 43.2 (95\%CI 9 to 78 ), IRR: 1.2 [95\%CI 0.5 to 2.9], p=0.7209 and

4 IRR: 2.0 [95\%CI 0.8 to 5.0], p=0.1617. Regarding non-contact injuries overall, a non-significant trend

5 towards an increased risk in the final match in the 2- and 3-match congestion cycles was also observed

6 compared to match-play outside cycles (Table 2). The risk of incurring a non-contact injury when the

7 player performed a 'change in direction' when running was significantly higher (21.6 [-3 to 46] vs. 2.8

8 [95\% CI -1 to 7], IRR: 7.8 [95\%CI 1.3, 46.8], p=0.0243) in the final match in 3-match congestion cycles

9 compared to match-play outside congestion cycles while a non-significant but increased risk was

10 observed in 2-match congestion cycles (IRR: 5.4 [95\%CI 1.0 to 29.3], p=0.052).

11 The risk of injury occurring in the $1^{\text {st }}$-half as a whole in the final match in the 3-match congestion

12 cycle was significantly higher compared to match-play outside congestion cycles (Table 3): 50.4 (95\% CI

1313 to 88 ) vs. 19.4 (95\%CI 9 to 29 ), IRR: 2.6 [95\%CI 1.1 to, 6.5), p=0.0386. A substantially higher albeit

14 non significant risk of injury occurring in the first 15 -minutes of play was observed in the $1^{\text {st }}$-half in the

15 final match in the 3-match congestion cycle compared to match-play outside congestion cycles: 14.4 16 (95\% CI -6 to 34) vs. 1.4 (95\% CI -1 to 4), IRR: 10.4 [95\% CI 1.0 to 114.9), p=0.057. A significantly higher 17 risk of injury was observed from 75-minutes play onwards in the final match in the 2-match congestion 18 cycle compared to in matches outside congestion cycles: 26.0 ( 7 to 45 ) vs. 8.3 ( 2 to 15 ), IRR: 3.1 (95\%CI 19 1.1 to 9.3$), \mathrm{p}=0.0400$.

\section{Discussion}

22 The aim of the present study was to analyse the impact of match congestion on injury risk and patterns in 23 players belonging to a professional football club. In the same players, main findings revealed that there was a significantly greater risk of sustaining an injury in the final 15-minutes of play in the second match in a congested cycle of two consecutive matches separated by $\leq 3$ days interval in comparison to matchplay outside the congested cycle. There was also a significantly greater overall risk of sustaining injury, particularly in the $1^{\text {st }}$-half of play, incurring an ankle sprain and a non-contact injury due to a "change in direction' in the third match in a cycle of 3 matches played successively within a $\leq 4$-day period in comparison to match-play outside the congested cycle. In contrast, the risk of re-injury and mean layoff time per injury were not increased in the final match during the congested cycles.

32 Injury rates

33 In previous studies on the effects of match congestion on injury rates in professional football, a trend for 34 a higher risk of sustaining injury in match-play over short congested periods has generally been reported 35 irrespective of study design. Incidence rate ratio values derived from reported data for short congested 36 periods ( $\leq 4$ days interval between matches versus $\geq 6$ days interval) range from a 1.1 (29.0 vs. 26.6, $37 \mathrm{p}=0.045)^{2}$ to a $5.1(97.7 \text { vs. } 19.3, \mathrm{p}<0.001)^{4}$ fold greater risk of sustaining a time-loss injury. However, a 
common limitation in previous study designs is the failure to account for player rotation ${ }^{5}$ and there is a need for comparisons in the same players when they compete in and outside of congested fixture periods. In the present investigation, incidence rate ratios within the aforementioned range were nevertheless reported with a 1.5 and 2.0-fold greater risk (the latter significantly) in the same players in the final match over the two short congestion cycles compared to match-play outside the cycles. Thus, these findings further confirm that exposure to short periods of fixture congestion increases the risk of injury in elite players. However, in previous studies ${ }^{2,3,5,6}$, lower values for injury incidences (injuries per 1000 hours exposure time) have generally been reported over congested fixture periods. Here, only data in the same players who were regularly exposed to fixture congestion and had a minimum of 75-minutes participation time were analysed potentially providing a more realistic representation of the injury risk. Indeed, previous research has generally analysed injury data at a team level ${ }^{2,3,5,6}$ and the lower injury incidence values reported during congested fixture periods could be linked to player rotation policies that diluted

13 the real risk of injury (e.g., sporadic exposure over the season, players only competing in 1 out of 2 matches in cycles played in a short time frame, <75-minutes exposure time).

In relation to the above findings, it is noteworthy that the high risk of injury related to fixture congestion observed in the present cohort occurred despite the systematic injury prevention (Nordic hamstring lowers, joint proprioception exercises and core stability exercises) and recovery interventions

18 (e.g., contrast therapy, compression garments) performed by the players between matches over these 19 congested periods. ${ }^{4,6}$ This finding implies a need for re-examination of match scheduling at elite standards 20 to ensure that players have sufficient recovery time between matches.

Injury patterns

23 Limited information exists on the type and location of injuries occurring during short periods of match congestion. A significantly higher risk (IRR: 1.3) of sustaining a muscle injury was reported in 27 professional European football teams during fixture congestion. ${ }^{2}$ Here, for non-contact injuries as a whole and specifically muscle strains, a trend albeit non-significant towards an increased incidence in the final match in the 2- and 3-match congestion cycles was observed compared to match-play outside the cycles. In addition, while non-significant, there was a substantially greater risk of a strain to the hamstring region in both short congestion cycles (IRR: 2.0 and 2.6). Regarding ankle sprains, there was a 5.4 and 10.4 fold greater risk (the latter significantly) in the final match in the 2- and 3-match congestion cycles. Taken together, these results are noteworthy as they suggest the present players were more susceptible to noncontact injuries such as muscular strains and particularly joint sprain injuries during short periods of fixture congestion suggesting a potential link with the accumulation of fatigue and/or incomplete physical recovery. ${ }^{4}$ Of note is the substantially higher incidence of muscle strain in matches separated by $\leq 3$ days interval reported here compared to that observed in 27 elite European football teams (33.3 vs. 11.2). ${ }^{2}$ Again, this discrepancy across studies could be explained by the inclusion here of data solely collected 
Previous epidemiological research has shown that injury occurrence generally and the risk of

2 sustaining a strain to the hamstring region in particular are both augmented during the latter stages of

3 football match-play at elite standards. ${ }^{7,8}$ However, no information exists on the temporal distribution of

4 injuries incurred during periods of match congestion. Here, a significantly higher incidence of injuries

5 was reported at the end of games (from 75-minutes play onwards) in the final match in the 2-match

6 congestion cycles compared to in match-play outside the cycle. It is noteworthy that the majority (67\%)

7 of these injuries were muscle strains of which $75 \%$ were to the hamstring region. It has previously been

8 suggested that this time course susceptibility to muscular strain injury in the latter stages of match-play

9 is linked to structural changes in muscle and cumulative mechanical stress inducing altered running

10 kinematics. ${ }^{16}$ In addition, there was a significantly higher injury incidence in the first-half of play as a

11 whole in the final match in a 3-match congestion cycles compared to during the same time period in

12 match-play outside the cycle. Out of the injuries sustained, $57 \%$ were muscle strains and $28 \%$ sprains

13 while $43 \%$ were linked to a change in direction when running. When combined with the 8 -fold

14 significantly greater risk of incurring a non-contact injury generally due to a 'change in direction' when

15 running identified in the final match in the 3-match congestion cycles, these results tend to support the

16 potential association between accumulated fatigue and impaired sprinting mechanics, muscular strength

17 and joint stability. ${ }^{17}$ Future work could attempt to identify potential trends in the temporal distribution

18 and causes of injury in relation to match type and the typical schedules faced by teams (e.g., European

19 competition followed by League match).

21 Practical implications

22 In light of these findings, there are implications for practitioners as regards to player substitution and

23 rotation strategies in an attempt to reduce the time-related risk of injury presently identified over short

24 periods of match congestion. There is also a need for investigations in which players perform consecutive

25 football-specific 90-minute intermittent running protocols that simulate the demands of match-play over

26 'congested' time scales similar to those employed here. This would enable analysis and potential

27 identification of the cumulative effect of successive matches during congested periods on physical and

28 physiological responses to play.

30 Limitations

31 A limitation acknowledged at the outset of this study was that the injury risk and patterns observed might

32 only reflect this present cohort of players from a single elite football club. Similar investigations involving

33 a larger sample of clubs internationally to increase statistical power and narrow the confidence intervals

34 for incidence rate ratios are necessary to verify the present findings. However, despite these limitations,

35 this study has merit in that it investigates injury and match congestion using measures of injury data and

36 exposure time in the same players. A further strength was its stringent inclusion criteria, six-season span 
1 and prospective methodology the latter respecting international recommended injury recording systems

2 thereby allowing injury data to be compared with future research findings.

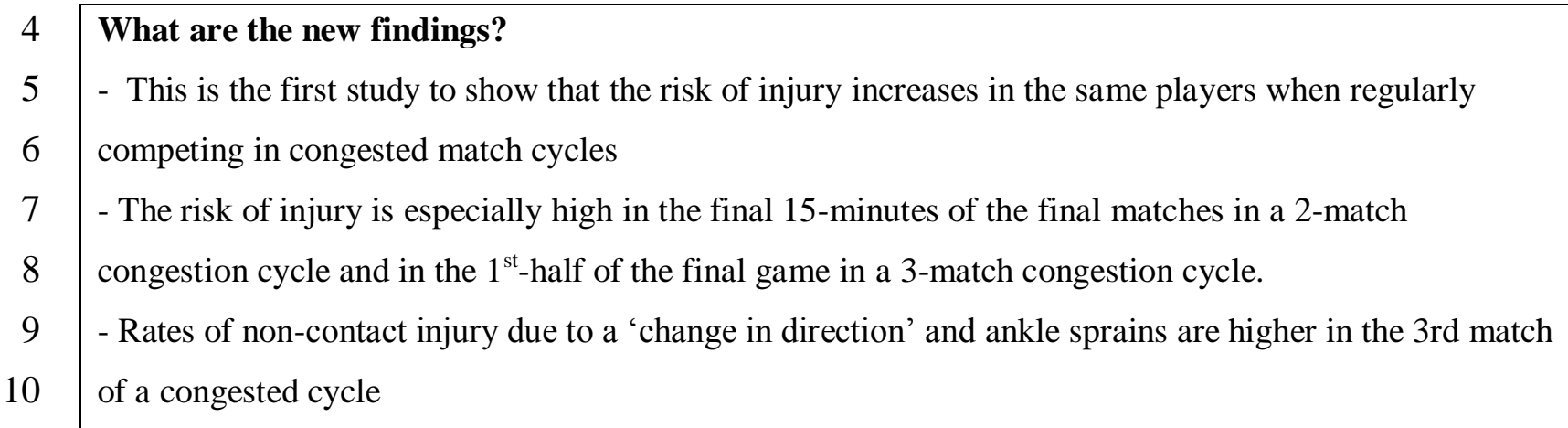

\section{How might it impact on clinical practice?}

13 - The findings support the importance of monitoring participation rates in players during congested match periods

- Provides an insight into the need for individualising player rotation and substitution strategies to reduce the injury risk

- Provides further support for UEFA recommendations that match schedules should be planned to ensure sufficient recovery time between matches

211 Ekstrand J, Waldén M, Hägglund M. A congested soccer calendar and the wellbeing of players: Correlation between match exposure of European soccer players before the World Cup 2002 and their injuries and performances during that World Cup. Br J Sports Med 2004;38:493-7.

242 Bengtsson H, Ekstrand J, Hagglund, M. Muscle injury rates in professional soccer increases with fixture congestion: an 11-year follow-up of the UEFA Champions League injury study. Br J Sports Med 2013;47:743-7.

3 Carling C, Orhant E, LeGall F. Match injuries in professional soccer: inter-seasonal

304 Dupont G, Nedelec M, McCall A, et al. Effect of 2 soccer matches in a week on physical performance and injury rate. Am J Sports Med 2010;38:1752-8.

325 Dellal A, Lago-Peñas C, Rey E, et al. The effects of a congested fixture period on physical performance, technical activity and injury rate during matches in a professional soccer team. $\mathrm{Br} J$ Sports Med. 2015;49:390-4. 
16 Carling C. Le Gall F, Dupont G. Are physical performance and injury risk in a professional 2 soccer team in match play affected over a prolonged period of fixture congestion? Int $J$ $3 \quad$ Sports Med 2011;32:1-7.

47 Hawkins RD, Hulse MA, Wilkinson C, et al. The association soccer medical research programme: $5 \quad$ an audit of injuries in professional soccer. Br J Sports Med 2001;35:43-7.

68 Woods C, Hawkins RD, Maltby S, et al. The Football Association Medical Research Programme: 7 an audit of injuries in professional football—analysis of hamstring injuries. Br J Sports Med $8 \quad 2004 ; 38(1): 36-41$

99 Woods C, Hawkins R, Hulse M, et al. The Football Association Medical Research Programme: an 10 audit of injuries in professional football: an analysis of ankle sprains Br J Sports Med 2003;37:233118 .

1210 Winter EM, Maughan RJ. Requirements for ethics approvals. J Sports Sci 2009;27:985.

1311 Carling C, McCall A, Le Gall F, et al. What is the extent of exposure to periods of match congestion 14 in professional soccer players? J Sports Sci, in press.

1512 Strudwick, T. (2012). Contemporary issues in the physical preparation of elite players. In:

16 M. Williams ed. Science \& Soccer III. London. Routledge, 335-356.

1713 Ispirlidis I, Fatouros IG, Jamurtas AZ, et al. Time-course of changes in inflammatory and 18 performance responses following a soccer game. Clin J Sports Med 2008;18:423-431.

1914 Fuller CW, Ekstrand J, Junge A, et al. Consensus statement on injury definitions and data collection 20 procedures in studies of soccer (soccer) injuries. Clin J Sports Med 2006;16:97-106.

2115 Hagglund M, Walden M, Bahr R, et al. Methods for epidemiological study of injuries to 22 professional soccer players: developing the UEFA model. Br J Sports Med 2005;39:340-6.

2316 Small K, McNaughton L, Greig M, et al. The effects of multidirectional soccer-specific fatigue on markers of hamstring injury risk. J Sci Med Sport 2010;13:120-5.

17 Greig, M. The influence of soccer-specific activity on the kinematics of an agility sprint, Eur $J$ 
1 Figure 1 Incidence of injury in the final match of short congested match cycles compared to during match-play outside the congested cycles.

4 Injury incidences are presented with $95 \%$ Confidence Intervals bars

5 2-match congestion cycle: two successive matches separated by a time interval totalling $\leq 3$ days ( $\leq 72 \mathrm{hrs})$ calculated immediately from the end of play in match 1 to the beginning of play in match 2

63 -match congestion cycle: three matches played successively with each separated by a $\leq 4$-day period commencing the day immediately after each match 
1 Table 1 Incidence of major injury types and locations in the final match in short congested match cycles compared to during match-play outside the cycles.

2

\begin{tabular}{|l|c|c|c|c|c|c|c|}
\hline $\begin{array}{l}\text { Incidence of injury } \\
\text { type and location }\end{array}$ & Match outside & \multicolumn{4}{|c|}{ Final match in congested periods of } & \multicolumn{4}{|c|}{ IRR (95\% CI) for match-play outside congestion vs. final match in congested cycles } \\
congested periods & 2 matches $\leq 3$ days & 3 matches $\leq 4$ days & 2 matches $\leq 3$ days & $\mathrm{p}$ & 3 matches $\leq 4$ days & $\mathrm{p}$ \\
\hline Strains & $16.6(7,26)$ & $33.3(12,55)$ & $36.0(4,68)$ & $2.0(0.8,4.8)$ & 0.1120 & $2.2(0.8,6.2)$ & 0.1453 \\
\hline Hamstring & $11.1(3,18)$ & $22.3(5,40)$ & $28.8(1,57)$ & $2.0(0.7,5.8)$ & 0.1944 & $2.6(0.8,8.7)$ & 0.1179 \\
\hline Quadriceps & 0.0 & 0.0 & $7.2(-7,21)$ & & & & \\
\hline Groin & $1.4(-1,4)$ & $3.7(-4,11)$ & 0.0 & $2.7(0.2,43.0)$ & 0.4845 & & \\
\hline Calf & $4.1(-1,9)$ & 0.0 & 0.0 & & & & \\
\hline Other & 0.0 & $7.4(-3,18)$ & 0.0 & & & & \\
\hline Sprains & $4.1(0,9)$ & $14.9(0,29)$ & $28.8(1,57)$ & $3.6(0.8,16.2)$ & 0.0947 & $7.0(1.5,31.4)$ & 0.0112 \\
\hline Ankle & $2.8(-1,7)$ & $14.9(0,29)$ & $28.8(1,57)$ & $5.4(1.0,29.3)$ & 0.0522 & $10.4(1.9,57.9)$ & 0.0068 \\
\hline Knee & $1.4(-1,4)$ & & & & & & \\
\hline Contusion & $19.4(9,29)$ & $14.9(0,29)$ & $12.8(-6,34)$ & $0.8(0.3,2.3)$ & 0.6794 & $0.7(0.2,2.2)$ & 0.6519 \\
\hline
\end{tabular}

3

Injury incidence values are presented with $95 \%$ Confidence Intervals

IRR: Incidence Rate Ratios 
1 Table 2 Incidence of non-contact injury and causes in the final match in short congested match cycles compared to during match-play outside cycles.

\begin{tabular}{|c|c|c|c|c|c|c|c|}
\hline \multirow{2}{*}{$\begin{array}{l}\text { Cause of non-contact } \\
\text { injury incidence }\end{array}$} & \multirow{2}{*}{$\begin{array}{c}\text { Match outside } \\
\text { congested periods }\end{array}$} & \multicolumn{2}{|c|}{ Final match in congested periods of } & \multicolumn{4}{|c|}{ IRR (95\% CI) for match-play outside congestion vs. final match in congested cycles } \\
\hline & & 2 matches $\leq 3$ days & 3 matches $\leq 4$ days & 2 matches $\leq 3$ days & $\mathrm{p}$ & 3 matches $\leq 4$ days & $\mathrm{p}$ \\
\hline Non-contact injury & $24.9(13,36)$ & $44.6(19,70)$ & $50.4(13,88)$ & $1.8(0.9,3.7)$ & 0.1177 & $2.0(0.9,4.8)$ & 0.1129 \\
\hline Acceleration & $5.5(0,11)$ & $7.4(-3,18)$ & 0.0 & $1.3(0.2,7.3)$ & 0.7330 & & \\
\hline Change in direction & $2.8(-1,7)$ & $14.9(0,29)$ & $21.6(-3,46)$ & $5.4(1.0,29.3)$ & 0.0522 & $7.8(1.3,46.8)$ & 0.0243 \\
\hline Fall & $2.8(-1,7)$ & $4(-4,11)$ & 0.0 & $1.3(0.1,14.8)$ & 0.8094 & & \\
\hline Kicking ball & $1.4(-1,4)$ & $3.7(-4,11)$ & 0.0 & $2.7(0.2,43.0)$ & 0.4845 & & \\
\hline Landing & $1.4(-1,4)$ & 0.0 & 0.0 & & & & \\
\hline Tackle & 0.0 & $3.7(-6,8)$ & $7.2(-6,21)$ & & & & \\
\hline Unknown & $11.1(3,19)$ & $11.1(-1,24)$ & $21.6(-3,46)$ & $1.0(0.3,3.8)$ & 0.9909 & $2.0(0.5,7.3)$ & 0.3224 \\
\hline
\end{tabular}

4 Injury incidence values are presented with $95 \%$ Confidence Intervals

5 IRR: Incidence Rate Ratios 
1 Table 3 Incidence of injury according to time period in the final match in short congested match cycles compared to during match-play outside cycles.

\begin{tabular}{|c|c|c|c|c|c|c|c|}
\hline \multirow{2}{*}{$\begin{array}{l}\text { Injury incidence } \\
\text { across time periods }\end{array}$} & \multirow{2}{*}{$\begin{array}{c}\text { Match outside } \\
\text { congested periods }\end{array}$} & \multicolumn{2}{|c|}{ Final match in congested periods } & \multicolumn{4}{|c|}{ IRR $(95 \% \mathrm{CI})$ for match-play outside congestion vs. final match in congested cycles } \\
\hline & & 2 matches $\leq 3$ days & 3 matches $\leq 4$ days & 2 matches $\leq 3$ days & $\mathrm{p}$ & 3 matches $\leq 4$ days & $\mathrm{p}$ \\
\hline 1st half overall & $19.4(9,29)$ & $26.0(7,45)$ & $50.4(13,88)$ & $1.3(0.3,5.3)$ & 0.5234 & $2.6(1.1,6,5)$ & 0.0386 \\
\hline $0-15 \mathrm{mins}$ & $1.4(-1,4)$ & $4(-6,8)$ & $14.4(-6,34)$ & $2.7(0.2,43.0)$ & 0.4845 & $10.4(1.0,114.9)$ & 0.0557 \\
\hline 16-30mins & $9.7(3,17)$ & $11.1(-2,24)$ & $21.6(-3,46)$ & $1.2(0.3,4.5)$ & 0.8378 & $2.2(0.6,8.6)$ & 0.2443 \\
\hline 31mins-Half-time & $8.3(2,15)$ & $11.1(-2,24)$ & $14.4(-6,34)$ & $1.3(0.3,5.3)$ & 0.6761 & $1.7(0.4,8.6)$ & 0.4989 \\
\hline 2nd half overall & $19.4(9,29)$ & $37.1(14,60)$ & $28.8(1,57)$ & $1.9(0.9,4.3)$ & 0.1153 & $1.5(0.5,4.5)$ & 0.4828 \\
\hline $45-60 \mathrm{mins}$ & $8.3(2,15)$ & $3.7(-6,8)$ & $7.3(-7,21)$ & $0.5(0.1,3.7)$ & 0.7150 & $0.9(0.1,7.2)$ & 0.5397 \\
\hline $61-75 \mathrm{mins}$ & $2.8(-1,7)$ & $7.4(-3,18)$ & $7.3(-7,21)$ & $2.7(0.4,19.1)$ & 0.3229 & $2.6(0.2,28.2)$ & 0.4343 \\
\hline 75mins-end match & $8.3(2,15)$ & $26.0(7,45)$ & $14.4(-6,34)$ & $3.1(1.1,9.3)$ & 0.0400 & $1.7(0.4,8.6)$ & 0.4989 \\
\hline Unknown & $8.3(2,15)$ & $7.4(-3,18)$ & $14.4(-6,34)$ & $0.9(0.2,4.4)$ & 0.5536 & $1.7(0.4,8.6)$ & 0.4989 \\
\hline
\end{tabular}

